\title{
Diagnostic Value of the Neutrophil/Lymphocyte Ratio, Platelet/Lymphocyte Ratio, and Thrombocytosis in the Preoperative Investigation of Ovarian Masses
}

\section{Valor diagnóstico das razões neutrófilo/linfócito, plaqueta/ linfócito, e trombocitose na investigação pré-operatória de} massas ovarianas

\author{
Adriana Yoshida10 Luís Otavio Sarian ${ }^{10}$ Marcos Marangoni Junior ${ }^{10}$ Isis Caroline Firmano ${ }^{10}$
} Sophie Françoise Derchain ${ }^{10}$

\author{
${ }^{1}$ Department of Obstetrics and Gynecology, Faculty of Medical \\ Sciences, Universidade Estadual de Campinas, Campinas, São Paulo, \\ Brazil
}

Rev Bras Ginecol Obstet 2020;42(7):397-403.

\author{
Address for correspondence Adriana Yoshida, MD, PhD, Cidade \\ Universitária Zeferino Vaz - Barão Geraldo, Campinas, SP, 13083-970, \\ Brazil (e-mail: adriana122013@gmail.com).
}

\begin{abstract}
Keywords

- adnexal masses

- diagnosis

- ovarian cancer

- serum biomarkers

- thrombocytosis
\end{abstract}

\section{Resumo}

received

September 11, 2018

accepted

April 23, 2020
Objective To evaluate the diagnostic accuracy of cancer antigen 125 (CA125) and complete blood count $(\mathrm{CBC})$ parameters, such as the neutrophil to lymphocyte ratio (NLR), the platelet to lymphocyte ratio (PLR), and thrombocytosis in patients with ovarian masses.

Methods The present is a retrospective study conducted at a single tertiary hospital from January 2010 to November 2016. We included consecutive women referred due to suspicious adnexal masses. The CBC and CA125 were measured in the serum of 528 women with ovarian masses before surgery or biopsy. We evaluated the diagnostic performance of the NLR, PLR, platelets (PLTs), CA125, and the associations between them. We tested the clinical utility of the $C B C$ parameters and CA125 in the discrimination of ovarian masses through decision curve analysis (DCA).

Results The best balance between sensitivity and specificity was obtained by the associations of CA 125 or PLTs $\geq 350 / n L$, with $70.14 \%$ and $71.66 \%$, CA 125 or PLTs $\geq 400$ / $\mathrm{nL}$, with $67.30 \%$ and $81.79 \%$, CA125 or PLR, with $76.3 \%$ and $64.87 \%$, and CA125 or NLR, with $71.09 \%$ and $73.89 \%$ respectively. In the DCA, no isolated CBC parameter presented a higher clinical utility than CA125 alone.

Conclusion We showed that no CBC parameter was superior to CA125 in the prediction of the malignancy of ovarian tumors in the preoperative scenario.

Objetivo Avaliar a acurácia diagnóstica do antígeno de câncer 125 (cancer antigen 125, CA125, em inglês) e dos parâmetros do hemograma como as razões neutrófilo/linfócito (RNL), plaqueta/linfócito (RPL), e trombocitose em pacientes com massas ovarianas.

Métodos Este é um estudo retrospectivo realizado em um hospital terciário no período de janeiro de 2010 a novembro de 2016 . Foram incluídas de forma consecutiva
DOI https://doi.org/ 10.1055/s-0040-1712991. ISSN 0100-7203.
Copyright @ 2020 by Thieme Revinter

Publicações Ltda, Rio de Janeiro, Brazil
License terms

(c) (9) 


\author{
Palavras-chave \\ - massas anexiais \\ - diagnóstico \\ - câncer de ovário \\ - biomarcadores \\ séricos \\ - trombocitose
}

mulheres encaminhadas por massas anexiais suspeitas. Foram dosados hemogramas e CA125 no soro de 528 mulheres com massas ovarianas antes da cirurgia ou biópsia. Foram avaliados os desempenhos diagnósticos da RNL, da RPL, das plaquetas (PLQs) e do CA125, considerando-os isoladamente e associados entre si. Testamos a utilidade clínica dos parâmetros do hemograma e do CA125 na discriminação das massas ovarianas por análise de curva de decisão (ACD).

Resultados Os melhores equilíbrios entre sensibilidade e especificidade foram obtidos por meio das associações do CA125 ou PLQs $\geq 350 / \mathrm{nL}$, com $70,14 \%$ e $71,66 \%$, CA125 ou PLQs $\geq 400 / n L$, com 67,30\% e 81,79\%, CA 125 ou RPL, com 76,3\% e 64,87\%, e CA125 ou RNL, com $71,09 \%$ e $73,89 \%$, respectivamente.

Conclusão Na ACD, nenhum parâmetro do hemograma isolado se mostrou superior ao CA125 na predição de malignidade de tumores ovarianos no pré-operatório.

\section{Introduction}

Ovarian cancer $(\mathrm{OC})$ is the second most lethal gynecological cancer worldwide, although it is relatively rare. ${ }^{1}$ On the other hand, adnexal masses are frequently found on transvaginal ultrasonography or other imaging exams, and the diagnosis of these patients is challenging. The patients benefit from a more accurate preoperative diagnosis, since it may help in the medical decision-making regarding the adequate treatment or follow-up. The diagnostic accuracy of serum biomarkers has been evaluated, and although some approaches besides cancer antigen 125 (CA125) alone are commercially available, such as the risk of ovarian malignancy algorithm (ROMA, LabCorp, Burlington, NC, US) and OVA1 (Vermillion, Austin, TX, US), there is a gap of more simple and accessible tools to be widely used in a population with adnexal masses.

Since chronic inflammation plays a fundamental role in the pathogenesis of $\mathrm{OC}^{2}$ several studies ${ }^{3-8}$ have investigated systemic inflammatory response (SIR) markers obtained from a simple complete blood count $(\mathrm{CBC})$, such as the neutrophil to lymphocyte ratio (NLR), the platelet to lymphocyte ratio (PLR), and the platelet (PLT) count. They have been evaluated as relevant prognostic factors in $\mathrm{OC}^{3,4}$ but a few studies ${ }^{5-8}$ have focused their usefulness in the prediction of malignancy in the preoperative setting.

At the time of diagnosis, an elevated PLT count, namely thrombocytosis (PLT count $\geq 400 / \mathrm{nL}^{9}$ or $\geq 350 / \mathrm{nL}^{7}$ ), is found in women with ovarian cancer, and is associated to a decreased overall survival (OS) and poor prognosis. ${ }^{4}$ In the tumor and host tissues, there is an increased production of thrombopoietic cytokines (mainly IL-6 [Interleukin 6]), which leads to paraneoplastic thrombocytosis, resulting in tumor growth and progression. ${ }^{10}$ Moreover, the PLTs do not allow contact of the tumor cells with the host's immune system, preventing natural killer cell-mediated elimination of tumor cells and supporting the extravasation of tumor cells. ${ }^{11}$

In a recent systematic review ${ }^{12}$ and meta-analysis it was found that a high NLR was associated with decreased OS and event-free survival (EFS) in patients with gynecologic cancers (OC, cervical and endometrial). Studies have indicated that neutrophils inhibit the immune system and contribute to the creation of an inflammatory microenvironment, promoting tumor growth, vascularization and metastasis. ${ }^{12}$

Two meta-analyses ${ }^{3,13}$ assessed the prognostic value of NLR and PLR for long-term survival (OS and progression-free survival [PFS]) in OC patients. Overall, the pooled data provided evidence that both higher NLR and higher PLR predicted inferior survival outcomes. However, there is a lack of data about the role of $\mathrm{CBC}$ parameters in the preoperative diagnosis of women with adnexal masses, which could be useful especially in the case of equivocal imaging on ultrasonography.

The present study aimed to investigate if there is a role for these parameters (alone or combined with CA125) in the preoperative discrimination of ovarian tumors. Our hypothesis is that CBC parameters, especially the PLR and thrombocytosis, might be better predictors of malignancy than isolated CA125.

\section{Methods}

The present is a retrospective study that evaluated women from January 2010 to November 2016 at the women's hospital (Centro de Atenção Integral à Saúde da Mulher, CAISM, in Portuguese) of Universidade Estadual de Campinas, a tertiary cancer center specialized in gynecological malignancies. The university's Ethics in Research Committee approved the study (under number 1092/2009). The eligibility criteria were women referred to the pelvic oncology clinic due to adnexal masses detected on ultrasound or another imaging exam, who had a $\mathrm{CBC}$ before they were submitted to surgery or percutaneous biopsy. The patients were consecutively included after signing a consent form, and they were submitted to the study protocol. First, they were submitted to a physical exam, and a pelvic ultrasound was scheduled. Blood samples were collected for serum tumor marker (CA125) and CBC measurement. Although samples for the biomarker and $\mathrm{CBC}$ dosage were not collected at the same moment, both were done before surgery or diagnostic biopsy. Diagnostic and/or surgical procedures were scheduled after the evaluation of the pelvic ultrasound, the CA125 dosage and the physical exam.

For this diagnostic accuracy study, the sample size was calculated based on the following parameters: expected 
specificity of $80 \%$, with a delta of $15 \%$, and study power of $90 \%$ ( $\beta$ error of $10 \%$ ). In addition, we used $95 \%$ confidence intervals (95\% CIs, $p=0.05$ ), denoting an allowed $\alpha$ error of $5 \%$. With these parameters, 85 patients with malignant ovarian tumors and another 85 patients without malignant ovarian tumors must be included. The calculations were based on the formulas provided in the appendix of Flahault et al, ${ }^{14}$ using the "power. diagnostic.test" function of the MKmisc library for the $\mathrm{R}$ Environment ( $R$ Foundation for Statistical Computing, Vienna Austria). In the present study, we enrolled 1,312 consecutive women, and we excluded those with no surgical indication (626 women), those without preoperative CBC ( 89 women), and those who had ovarian benign tumors ( 37 women), such as uterine leiomyoma, tubal cysts, sactosalpinx, and other ovarian malignant tumors (32 women), such as, endometrial cancer and carcinomas of gastrointestinal origin In total, 528 women with ovarian tumors were included (-Fig. 1). Percutaneous biopsies of pelvic masses or abdominal implants were performed in cases of non-resectable ovarian tumors. Tissue specimens were analyzed by pathologists specialized in gynecologic pathology, according to the guidelines of the World Health Organization's (WHO) International Classification of Ovarian Tumors. ${ }^{15}$ For tumor staging, we followed the classification of the International Federation of Gynecologists and Obstetricians (FIGO). ${ }^{16}$ Bilateral tumors were found in 104 women; for the purpose of categorization, the tumor with worst prognosis was taken into account. Postmenopausal status was defined as $>1$ year of amenorrhea or $\geq 50$ years of age in the case of previous hysterectomy. Five women did not have a preoperative CA125 dosage, but were not excluded from the study. No patient underwent chemotherapy before surgery or biopsy of the tumor in our casuistic.

\section{CA125 Measurement}

We collected blood samples from patients by puncture of a peripheral vein before surgery or percutaneous biopsy, and the samples were stored in serum separator tubes for the
CA125 dosage. For the majority of the women, serum CA125 was determined by the CA125 II test, through the electrochemiluminescence technique in the Cobas e411 (Roche Diagnostics GmbH, Mannheim, Germany) automatic analyzer, according to the manufacturer's instructions. The other women had their serum CA125 concentrations measured by the Architect (Abbott Diagnostics, Abbott Park, IL, US) automated assay, a two-step chemiluminescent microparticle immunoassay (CMIA), according to the manufacturer instructions, or by solid-phase chemiluminiscence in an automated system, using the OM-MA (Siemens Medical Solutions Diagnostics, Tarrytown, NY, US) test, according to the manufacturer's instructions. All CA125 values were expressed in units per milliliter $(\mathrm{U} / \mathrm{mL})$. The levels of CA125 were considered elevated if $\geq 35 \mathrm{U} / \mathrm{mL}$.

\section{Complete Blood Count}

The $\mathrm{CBC}$ was obtained from patients before the surgery or the percutaneous biopsy were performed. If the patient had more than one preoperative $\mathrm{CBC}$, we chose the nearest to the surgery/biopsy for analysis. The $\mathrm{CBC}$ was obtained through the automated hematology analyzer Sysmex XE2100 (TOA Medical Electronics, Kobe, Japan) from 2010 until 2012, according to the manufacturer's instructions. After 2012, the analyzer used was the Sysmex XE 5000 (TOA Medical Electronics). According to our receiver operating characteristic (ROC) curve analyses, the optimal cutoff point for elevated PLR was considered if $\geq 150.9$, and elevated NLR was considered if $\geq 2.9$. Cutoff points for thrombocytosis (PLT $\geq 350 / \mathrm{nL}$ and PLT $\geq 400 / \mathrm{nL}$ ) were obtained from large studies on the subject. ${ }^{7,9}$

\section{Statistical Analysis}

The data were analyzed using the $\mathrm{R}$ Environment for Statistical Computing software (R Foundation for Statistical Computing). ${ }^{17}$ Statistical calculations were performed using $95 \%$ CIs, considering $p$ values $<0.05$ as significant.

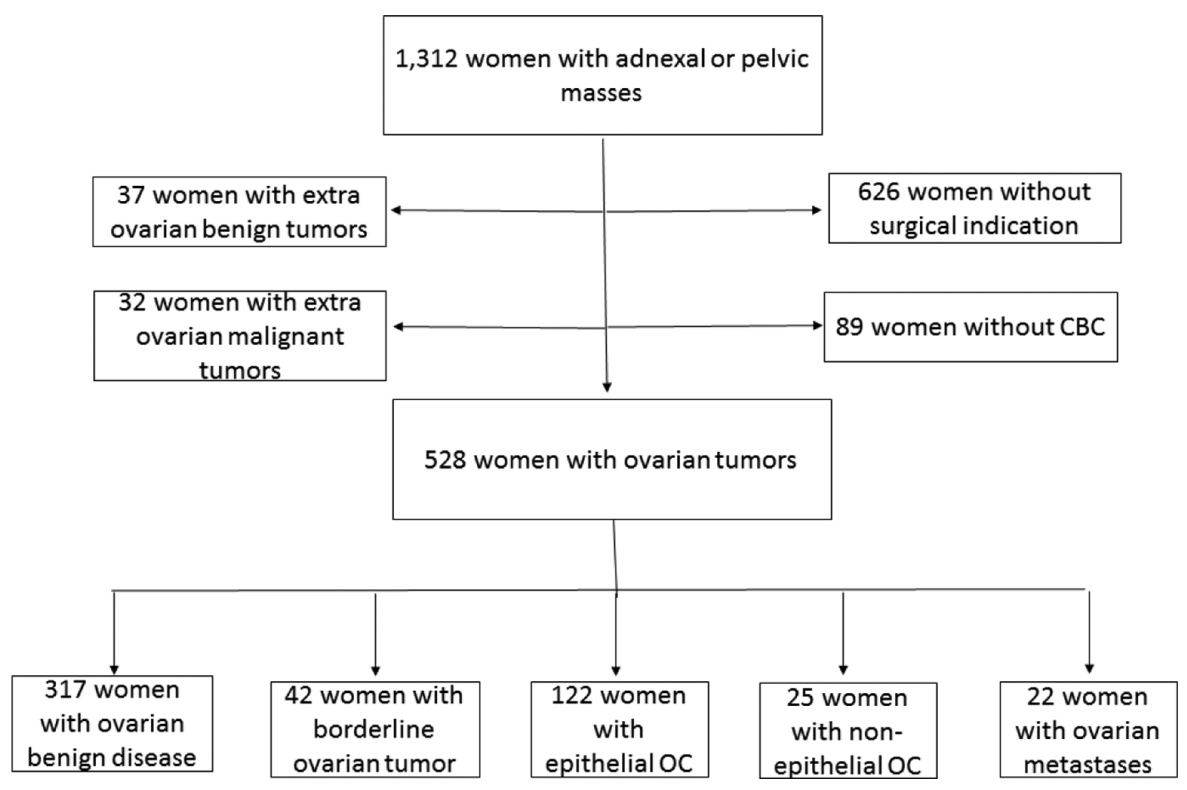

Fig. 1 Flowchart of the women included in the study. Abbreviations: CBC, complete blood count; OC, ovarian cancer. 
Ovarian tumors were classified into benign diseases (nonneoplastic and benign ovarian tumors), borderline ovarian tumor (BOT), epithelial ovarian cancer (EOC), non-epithelial ovarian cancer (non-EOC), and ovarian metastatic groups according to the histopathologic diagnosis, using the current criteria as proposed by Kurman el al. ${ }^{15}$ We determined the mean (with corresponding standard deviation [SD]) values for age, body mass index (BMI), serum CA125 levels, NLR, PLR and PLT levels, according to tumor groups. Data on BMI was not available for ten women. For further analysis, the BOT, EOC, non-EOC and ovarian metastatic groups were considered malignant. We then calculated the sensitivity, specificity, positive predictive value (PPV), negative predictive value (NPV), positive likelihood ratio (LR), negative LR, and accuracy for CA125, NLR, PLR, PLTs $\geq 350 / \mathrm{nL}$, PLTs $\geq 400 / \mathrm{nL}$, and the associations of 2 parameters (combinations were considered positive in different circumstances: when the CA125 and the CBC parameter were both positive, and when the CA125 or the $\mathrm{CBC}$ parameter were positive) to test the diagnostic performance for the prediction of malignancy. The cutoff values for the NLR and PLR (-Fig. 2) were obtained from the ROC curve (NLR $\geq 2.9$ and PLR $\geq 150.9$ ). Finally, we performed decision curve analysis (DCA) to test which parameters or their associations presented the best clinical utility to differentiate benign from malignant masses. For this graphic analysis, we used software designed specifically for DCA. ${ }^{18}$ All DCA calculations were performed as described by Vickers and Elkin. ${ }^{19}$

\section{Results}

- Table 1 shows the clinical features of patients and their tumors, and the CA125 levels and CBC parameters of 528 women included in the study. Benign ovarian diseases com- prised $27.4 \%$ of non-neoplastic ovarian lesions, and $72.6 \%$ of benign ovarian tumors. Among the malignant tumors, $19.9 \%$ were BOTs, $10.4 \%$ were ovarian metastases, $57.8 \%$ were EOCs, and $11.8 \%$ were non-EOCs. The total malignancy prevalence of our cohort was of $39.96 \%$. Women with EOC had a mean age of 59.22 years (SD: 14.42 years), and those with ovarian metastases had a mean age of 53.45 years (SD: 11.08 years), while women with benign ovarian diseases, as well as those with BOTs and non-EOCs, had a mean age $<50$ years. In total, $75 \%$ of the women with EOC were postmenopausal. Regarding the stage of the disease, it was initial for $83.3 \%$ of the women with BOTs, $47.5 \%$ of the women with EOCs, and $96 \%$ of those with non-EOCs.

- Table 2 shows the preoperative diagnostic performance of CA125, PLT, NLR and PLR in a pool of women with ovarian masses. Overall, the isolated $\mathrm{CBC}$ parameters tested showed low sensitivity, but high specificity to differentiate benign from malignant ovarian tumors. The best balance between sensitivity and specificity was when we used CA125 or PLT $\geq 350 / \mathrm{nL}$, with $70.14 \%$ and $71.66 \%$, CA125 or PLT $\geq 400 /$ nL with $67.30 \%$ and $81.79 \%$, CA125 or PLR, with $76.3 \%$ and $64.87 \%$, and CA125 or NLR, with $71.09 \%$ and $73.89 \%$ of sensitivity and specificity respectively. These associations showed a slight gain in sensitivity but a decrease in specificity when compared with isolated CA125. Moreover, thrombocytosis (PLT $\geq 400$ ) alone, or associated to CA125, thrombocytosis (PLT $\geq 350$ ) and PLR with a cutoff point of 150.9 associated to CA125 achieved specificities higher than 95\%, in spite of low sensitivities. In addition, the PPV of the association of CA125 and PLT $\geq 350$, PLT $\geq 400$, and PLR were remarkably high: $91.18 \%, 95.45 \%$ and $85.85 \%$ respectively, whereas the PPV of CA125 alone was of 73.45\%. - Table 2 also lists the accuracy of the separate and combined tests for the differentiation of benign from borderline and OC (accuracy) and to discern benign from borderline and stage I OCs
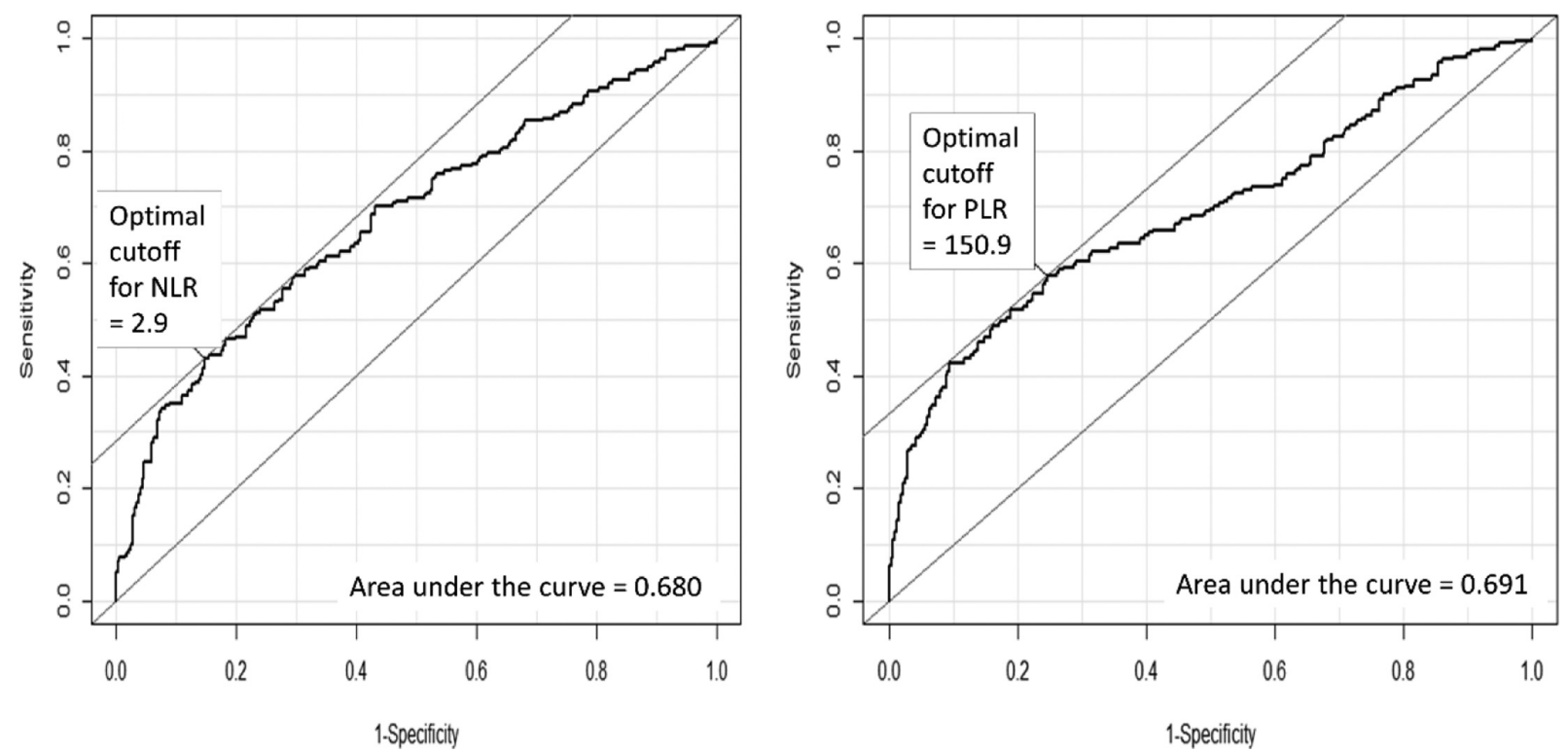

Fig. 2 Analyses of the receiver operating characteristic (ROC) curve of the A) neutrophil to lymphocyte ratio (NLR) and B) platelet to lymphocyte ratio (PLR) for the diagnosis of malignant tumors in women with adnexal masses. The optimal cutoff points are shown in the figures, along with the performance indicators (sensitivity, specificity) and the areas under the curves. 
Table 1 Clinical features of the women by type of tumor

\begin{tabular}{|c|c|c|c|c|c|}
\hline & $\begin{array}{l}\text { Benign }{ }^{\ddagger} \text { disease } \\
(n=317)\end{array}$ & $\begin{array}{l}\text { Borderline } \\
\text { ovarian tumor } \\
(n=42)\end{array}$ & $\begin{array}{l}\text { Epithelial } \\
\text { OC }(n=122)\end{array}$ & $\begin{array}{l}\text { Non-epithelial } \\
\text { OC }(n=25)\end{array}$ & $\begin{array}{l}\text { Ovarian } \\
\text { metastases } \\
(n=22)\end{array}$ \\
\hline$\overline{\text { Age, in years }}{ }^{\dagger}$ & $46.79(16.17)$ & $48.37(16.22)$ & $59.22(14.42)$ & $43.58(18.17)$ & $53.45(11.08)$ \\
\hline Premenopausal, n (\%) & $177(55.84)$ & $20(47.62)$ & 30 (24.59) & $14(56.0)$ & $11(50)$ \\
\hline Postmenopausal, n (\%) & $140(44.16)$ & $22(52.38)$ & $92(75.41)$ & $11(44.0)$ & $11(50)$ \\
\hline $\begin{array}{l}\text { Body Mass Index, } \\
\text { in } \mathrm{Kg} / \mathrm{m}^{2 \dagger}\end{array}$ & $28.57(5.79)$ & $28.67(5.49)$ & $27.17(5.76)$ & $28.42(6.51)$ & $27.43(4.93)$ \\
\hline $\mathrm{CA} 125$, in $\mathrm{U} / \mathrm{ml}^{\dagger}$ & $67.39(214.59)$ & $167.55(238.25)$ & $1156.73(3353.65)$ & $156.13(258.19)$ & $532.68(1469.04)$ \\
\hline Platelets/n| ${ }^{\dagger}$ & $\begin{array}{l}269,712.9 \\
(74,493.58)\end{array}$ & $\begin{array}{l}285,023.8 \\
(69,662.42)\end{array}$ & $\begin{array}{l}339,606.6 \\
(115,450.86)\end{array}$ & $\begin{array}{l}337,520.0 \\
(153,029.99)\end{array}$ & $\begin{array}{l}360,727.3 \\
(153,945.01)\end{array}$ \\
\hline $\begin{array}{l}\text { Neutrophil to } \\
\text { lymphocyte ratio }\end{array}$ & $2.20(1.35)$ & $2.87(2.43)$ & $3.81(3.22)$ & $2.63(1.50)$ & $9.43(15.03)$ \\
\hline $\begin{array}{l}\text { Platelet to } \\
\text { lymphocyte ratio }^{\dagger}\end{array}$ & $131.08(56.23)$ & $170.46(123.62)$ & 217.17 (155.09) & $183.69(95.35)$ & 311.09 (218.70) \\
\hline \multicolumn{6}{|l|}{ Disease stage } \\
\hline I-II, n (\%) & & $35(83.3)$ & $58(47.54)$ & $24(96)$ & \\
\hline III-IV, n (\%) & & $7(16.7)$ & $64(52.46)$ & $1(4)$ & \\
\hline
\end{tabular}

Abbreviations: CA125, cancer antigen 125; OC, ovarian cancer.

Notes:

†Values expressed as mean (standard deviation).

${ }^{\ddagger}$ Benign disease involves benign ovarian tumors and ovarian non-neoplastic lesions.

Table 2 Preoperative diagnostic performances of CA125, PLT, PLR and NLR

\begin{tabular}{|c|c|c|c|c|c|c|c|c|}
\hline & Sensitivity & Specificity & PPV & NPV & $\begin{array}{l}\text { Positive } \\
\text { LR }\end{array}$ & $\begin{array}{l}\text { Negative } \\
\text { LR }\end{array}$ & Accuracy & $\begin{array}{l}\text { Accuracy } \\
2^{*}\end{array}$ \\
\hline $\mathrm{CA} 125 \geq 35 \mathrm{U} / \mathrm{mL}$ & $61.90 \%$ (56.52 to 67.28$)$ & $84.98 \%$ (79.72 to 90.25$)$ & $73.45 \%$ & $76.88 \%$ & 4.12 & 0.45 & $75.72 \%$ & $72.6 \%$ \\
\hline $\mathrm{PLT} \geq 350 / \mathrm{nL}$ & $37.91 \%$ (32.57 to 43.25$)$ & $84.86 \%$ (78.65 to 91.07$)$ & $62.5 \%$ & $67.25 \%$ & 2.50 & 0.73 & $66.10 \%$ & $69.1 \%$ \\
\hline $\mathrm{PLT} \geq 400 / \mathrm{nL}$ & $25.59 \%$ (20.79 to 30.40$)$ & $96.21 \%(91.61$ to 100.82$)$ & $81.82 \%$ & $66.02 \%$ & 6.76 & 0.77 & $67.99 \%$ & $73.9 \%$ \\
\hline$P L R \geq 150.9$ & $57.82 \%$ (52.38 to 63.26$)$ & $75.08 \%$ (69.10 to 81.06$)$ & $60.70 \%$ & $72.78 \%$ & 2.32 & 0.56 & $68.18 \%$ & $68.0 \%$ \\
\hline $\mathrm{NLR} \geq 2.9$ & $42.65 \%$ (37.21 to 48.10$)$ & $85.17 \%$ (79.22 to 91.12$)$ & $65.69 \%$ & $69.05 \%$ & 2.88 & 0.67 & $68.18 \%$ & $71.3 \%$ \\
\hline $\begin{array}{l}\mathrm{CA} 125 \geq 35 \mathrm{U} / \mathrm{mL} \\
\text { or } \mathrm{PLT} \geq 350 / \mathrm{nL}\end{array}$ & $70.14 \%$ (65.08 to 75.20$)$ & $71.66 \%$ (65.92 to 77.39$)$ & $62.45 \%$ & $78.12 \%$ & 2.47 & 0.42 & $71.05 \%$ & $66.4 \%$ \\
\hline $\begin{array}{l}\mathrm{CA} 125 \geq 35 \mathrm{U} / \mathrm{mL} \\
\text { or } \mathrm{PLT} \geq 400 / \mathrm{nL}\end{array}$ & $67.30 \%$ (62.10 to 72.49$)$ & $81.79 \%$ (76.43 to 87.15$)$ & $71.36 \%$ & $78.77 \%$ & 3.69 & 0.40 & $75.95 \%$ & $72.6 \%$ \\
\hline $\begin{array}{l}\mathrm{CA} 125 \geq 35 \mathrm{U} / \mathrm{mL} \\
\text { and } \mathrm{PLT} \geq 350 / \mathrm{nL}\end{array}$ & $29.52 \%$ (24.49 to 34.55$)$ & $98.10 \%$ (94.86 to 101.34$)$ & $91.18 \%$ & $67.68 \%$ & 15.55 & 0.72 & $70.72 \%$ & $75.2 \%$ \\
\hline $\begin{array}{l}\mathrm{CA} 125 \geq 35 \mathrm{U} / \mathrm{mL} \\
\text { and PLT } \geq 400 / \mathrm{nL}\end{array}$ & $20 \%$ (15.60 to 24.40$)$ & $99.37 \%$ (97.03 to 101.71$)$ & $95.45 \%$ & $65.22 \%$ & 31.7 & 0.80 & $67.74 \%$ & $74.0 \%$ \\
\hline $\begin{array}{l}\text { CA } 125 \geq 35 \mathrm{U} / \mathrm{mL} \\
\text { or } \mathrm{PLR} \geq 150.9\end{array}$ & $76.30 \%$ (71.61 to 80.99$)$ & $64.87 \%$ (59.20 to 70.55$)$ & $59.19 \%$ & $80.39 \%$ & 2.17 & 0.36 & $69.45 \%$ & $65.0 \%$ \\
\hline $\begin{array}{l}\mathrm{CA} 125 \geq 35 \mathrm{U} / \mathrm{mL} \\
\text { and } \mathrm{PLR} \geq 150.9\end{array}$ & $43.33 \%$ (37.85 to 48.81$)$ & $95.22 \%$ (91.16 to 99.28$)$ & $85.85 \%$ & $71.53 \%$ & 9.07 & 0.59 & $74.43 \%$ & $75.6 \%$ \\
\hline $\begin{array}{l}C A 125 \geq 35 \mathrm{U} / \mathrm{mL} \\
\text { or } \mathrm{NLR} \geq 2.9\end{array}$ & $71.09 \%$ (66.08 to 76.10$)$ & $73.89 \%$ (68.23 to 79.54$)$ & $64.66 \%$ & $79.18 \%$ & 2.72 & 0.39 & $72.77 \%$ & $68.8 \%$ \\
\hline $\begin{array}{l}\mathrm{CA} 125 \geq 35 \mathrm{U} / \mathrm{mL} \\
\text { and NLR } \geq 2.9\end{array}$ & $33.33 \%(28.14$ to 38.53$)$ & $96.20 \%$ (92.07 to 100$)$ & $85.36 \%$ & $68.47 \%$ & 8.8 & 0.69 & $71.10 \%$ & $75 \%$ \\
\hline
\end{tabular}

Abbreviations: CA125, cancer antigen 125; LR, likelihood ratio; NLR, neutrophil to lymphocyte ratio; NPV, negative predictive value; PLR, platelet to lymphocyte ratio; PLT, platelet; PPV, positive predictive value.

Notes: The cutoff points for the PLR and NLR were derived from receiver operating characteristic (ROC) curve analysis (- Fig. 2), because there are no standard points reported in current medical literature. The cutoff points for CA125 levels and PLT counts are those used as standard in the medical literature. ${ }^{*}$ Accuracy for the differentiation of benign masses from borderline or stage I ovarian cancer (stage II or higher not included in this analysis). 


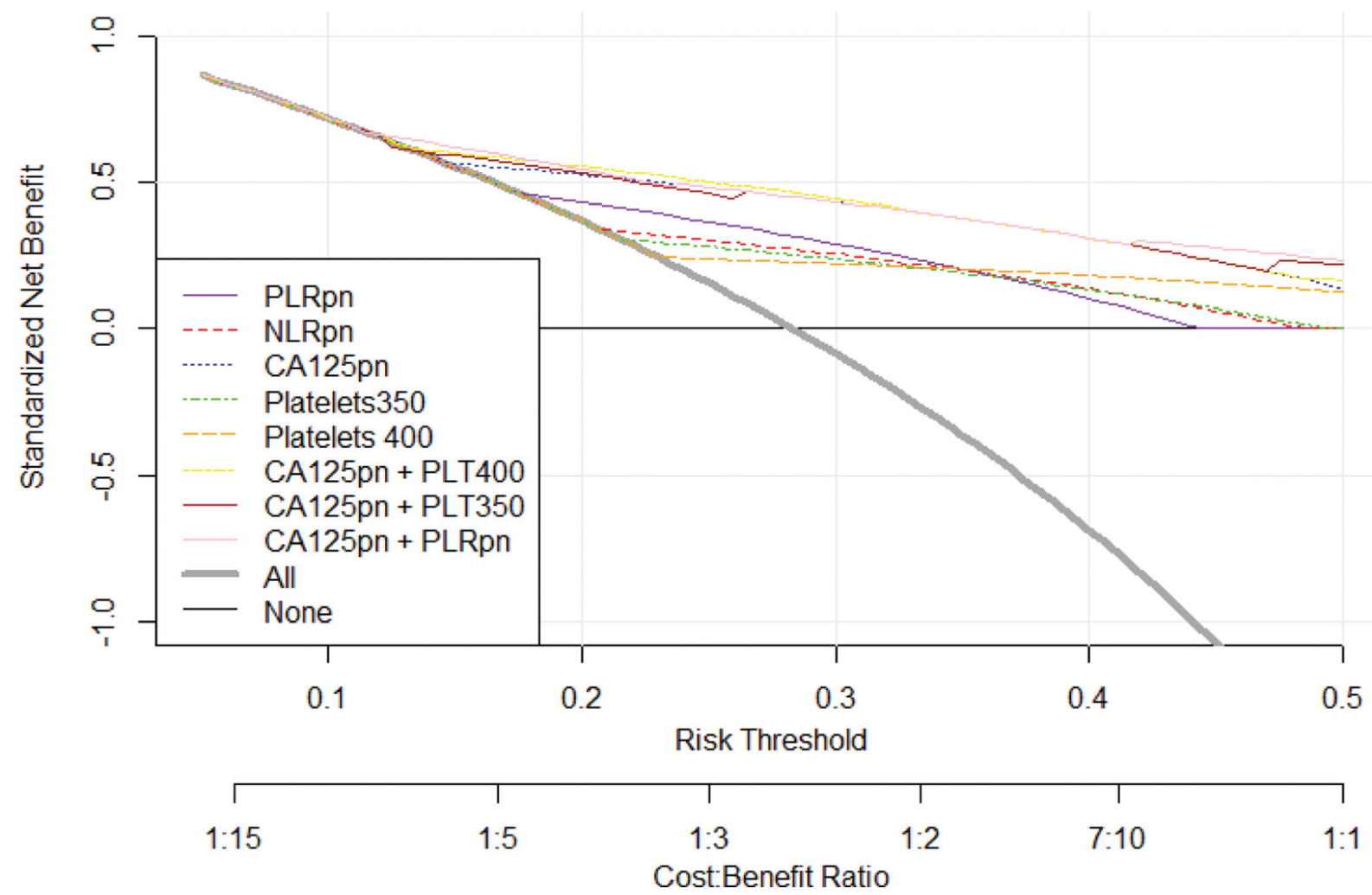

Fig. 3 Decision curve showing the net benefit of complete blood count parameters isolated or in association with CA125 in women at risk of developing ovarian cancer, borderline ovarian tumor and ovarian metastases. PLRpn, platelet to lymphocyte ratio, positive if $\geq 150.9$, negative if $<150.9$; NLRpn, neutrophil to lymphocyte ratio, positive if $\geq 2.9$, negative if $<2.9$; CA125pn, CA125 dosage, positive if $\geq 35 \mathrm{U} / \mathrm{mL}$, negative if $<35 \mathrm{U} / \mathrm{mL}$; Platelets 350 , platelets $\geq 350 / \mathrm{nL}$; Platelets 400 , platelets $\geq 400 / \mathrm{nL}$.

(accuracy 2. Please see the - Table 2). The best accuracy was obtained with CA125 as a separate test, and for the restricted dataset (excluding diseases in stage II or higher), the best accuracy was obtained with the combination of CA125 $\geq 35$ $\mathrm{U} / \mathrm{mL}$ AND PLR $\geq 150.9$.

-Fig. 3 shows the DCA for the CBC parameters and CA125. This graphic analysis showed that no isolated $\mathrm{CBC}$-derived parameter presented a higher clinical utility than CA125 alone. When we associated thrombocytosis (PLT $\geq 400 / \mathrm{nL}$ or PLT $\geq 350 / \mathrm{nL}$ ) and PLR with a cutoff point of 150.9 to CA125, we observed an enhancement of this clinical value, which was higher than the isolated CA125 clinical value in the range of $15 \%$ to $25 \%$ risks thresholds.

\section{Discussion}

In the present study, we evaluated and compared $\mathrm{CBC}$ parameters and the diagnostic accuracy of CA125 levels in a casuistic of 528 women with various histologic types of ovarian tumors. We showed that the NLR, the PLR or the thrombocytosis did not present a superior performance in the prediction of malignancy compared with CA125 dosage in the preoperative setting.

Chronic inflammation has been associated with the carcinogenesis of different types of tumors, including ovarian cancer (OC). This process occurs through different mechanisms such as inhibition of apoptosis, promotion of angiogenesis, stimulation of DNA damage, and up-regulation of cytokines and inflamma- tory mediators. In addition, SIR mediators impair the immune system, which leads to an increase in the concentrations of leukocytes, neutrophils, platelets, C-reactive protein (CRP) and fibrinogen, and a decrease in the levels of albumin and lymphocytes. ${ }^{20,21}$

Differently from Watrowski et $\mathrm{al}^{7}{ }^{7}$ in the present study, CA125 alone presented lower sensitivity and specificity in the differentiation of malignant and benign ovarian tumors. It is of note that, in their study, CA125 was available in $314 / 756$ (41.5\%) of the included individuals. However, when they associated CA125 with thrombocytosis, the specificity ( 0.94 for PLT $\geq 350$ and 0.96 for PLT $\geq 400$ ) and the PPV ( 0.91 for both cutoff points of PLT) were as high as in the present study. We obtained for the CA125 and PLT $\geq 350$ a specificity of $98.10 \%$, with a PPV of $91.18 \%$, and, for the CA125 and PLT $\geq 400$, a specificity of $99.37 \%$, with a PPV of $95.45 \%$, although the sensitivity in the present study was $<30 \%$ for both associations. In addition, in the study by Watrowski et $\mathrm{al}^{7}{ }^{7}$ thrombocytosis alone could improve the preoperative diagnosis of adnexal masses, but, in the present study, DCA showed that isolated thrombocytosis, PLR or NLR presented lower net benefit than CA125 alone or CA125 combined to the evaluated CBC parameters.

The NLR alone, with a cutoff of 2.9 , presented a low sensitivity (42.65\%), but a better specificity $(85.17 \%)$, in the prediction of malignancy in the present study. Moreover, DCA showed a low net benefit for NLR across the percentages of risk threshold. The cutoff points vary in the published studies, 
making it difficult to compare our results. Eo et al ${ }^{8}$ showed that the NLR (cutoff of 2.64), the PLR (cutoff 1of 91.71), elevated platelets, the CA125 and the lymphocyte-monocyte ratio (LMR) were able to predict EOC in a study involving 261 benign ovarian masses and 229 cases of EOC. However, it is important to note that we presented in our casuistic not only EOC, but a considerable number of non-epithelial, metastatic and borderline ovarian tumors, which reproduces a more realistic scenario of the clinical practice.

One systematic review ${ }^{22}$ showed that the PLR and NLR values in EOC patients deviate from that of healthy controls. However, their diagnostic accuracy remains limited, as their sensitivity and specificity were moderate $(55 \%$ to $80 \%$ of cases of OC detected), ${ }^{22}$ which corroborates our findings. Furthermore, this review ${ }^{22}$ points out that the diagnostic cutoff values are undefined until now. ${ }^{22}$

\section{Conclusion}

The present study has some limitations. Besides its retrospective nature, three different assays were used to measure CA125, and two automated hematology analyzers were used to obtain the preoperative $\mathrm{CBC}$. However, all of these assays were performed at a single institution, and the cutoff applied did not change along the period of the study, with no influence in the medical decision-making. On the other hand, the major strength was our relatively large casuistic, which involved not only EOC, but other less frequent histologic types of ovarian tumors, which may be found in the clinical practice. Finally, we showed that in the preoperative evaluation, no CBC parameter was superior to CA125 in the prediction of the malignancy of ovarian tumors.

\section{Contributors}

All authors were involved in the design and interpretation of the analyses, contributed to the writing of the manuscript, and read and approved the final manuscript.

\section{Conflicts to Interest}

The authors have no conflict of interests to declare.

\section{Acknowledgments}

The present study was supported by Fundação de Amapro à Pesquisa do Estado de São Paulo (Fapesp) under number 2012/15059-8.

\section{References}

1 Bray F, Ferlay J, Soerjomataram I, Siegel RL, Torre LA, Jemal A. Global cancer statistics 2018: GLOBOCAN estimates of incidence and mortality worldwide for 36 cancers in 185 countries. CA Cancer J Clin. 2018;68(06):394-424. Doi: 10.3322/caac.21492

2 Saed GM, Diamond MP, Fletcher NM. Updates of the role of oxidative stress in the pathogenesis of ovarian cancer. Gynecol Oncol. 2017;145(03):595-602. Doi: 10.1016/j.ygyno.2017.02.033

3 Zhao Z,Zhao X, Lu J, Xue J, Liu P, Mao H. Prognostic roles of neutrophil to lymphocyte ratio and platelet to lymphocyte ratio in ovarian cancer: a meta-analysis of retrospective studies. Arch Gynecol Obstet. 2018;297(04):849-857. Doi: 10.1007/s00404-018-4678-8
4 Ye Q, Cheng J, Ye M, Liu D, Zhang Y. Association of pretreatment thrombocytosis with prognosis in ovarian cancer: a systematic review and meta-analysis. J Gynecol Oncol. 2019;30(01):e5. Doi: 10.3802/jgo.2019.30.e5

5 Yildirim MA, Seckin KD, Togrul C, Baser E, Karsli MF, Gungor T, Gulerman HC. Roles of neutrophil/lymphocyte and platelet/lymphocyte ratios in the early diagnosis of malignant ovarian masses. Asian Pac J Cancer Prev. 2014;15(16):6881-6885. Doi: 10.7314/ apjcp.2014.15.16.6881

6 Bakacak M, Serin S, Ercan Ö, Köstü B, Bostancı MS, Bakacak Z, et al. Utility of preoperative neutrophil-to-lymphocyte and platelet-tolymphocyte ratios to distinguish malignant from benign ovarian masses. J Turk Ger Gynecol Assoc. 2016;17(01):21-25. Doi: 10.5152/jtgga.2015.0152

7 Watrowski R, Heinze G, Jäger C, Forster J, Zeillinger R. Usefulness of the preoperative platelet count in the diagnosis of adnexal tumors. Tumour Biol. 2016;37(09):12079-12087. Doi: 10.1007/ s13277-016-5090-2

8 Eo WK, Kim KH, Park EJ, Kim HY, Kim HB, Koh SB, Namkung J. Diagnostic accuracy of inflammatory markers for distinguishing malignant and benign ovarian masses. J Cancer. 2018;9(07): 1165-1172. Doi: $10.7150 /$ jca.23606

9 Menczer J. Preoperative elevated platelet count and thrombocytosis in gynecologic malignancies. Arch Gynecol Obstet. 2017;295 (01):9-15. Doi: 10.1007/s00404-016-4212-9

10 Stone RL, Nick AM, McNeish IA, Balkwill F, Han HD, Bottsford-Miller J, et al. Paraneoplastic thrombocytosis in ovarian cancer. N Engl J Med. 2012;366(07):610-618. Doi: 10.1056/NEJMoa1110352

11 Buergy D, Wenz F, Groden C, Brockmann MA. Tumor-platelet interaction in solid tumors. Int J Cancer. 2012;130(12):2747-2760. Doi: $10.1002 / \mathrm{ijc} .27441$

12 Ethier JL, Desautels DN, Templeton AJ, Oza A, Amir E, Lheureux S. Is the neutrophil-to-lymphocyte ratio prognostic of survival outcomes in gynecologic cancers? A systematic review and meta-analysis. Gynecol Oncol. 2017;145(03):584-594. Doi: 10.1016/j.ygyno.2017.02.026

13 Zhu Y, Zhou S, Liu Y, Zhai L, Sun X. Prognostic value of systemic inflammatory markers in ovarian Cancer: a PRISMA-compliant meta-analysis and systematic review. BMC Cancer. 2018;18(01): 443. Doi: 10.1186/s12885-018-4318-5

14 Flahault A, Cadilhac M, Thomas G. Sample size calculation should be performed for design accuracy in diagnostic test studies. J Clin Epidemiol. 2005;58(08):859-862. Doi: 10.1016/j.jclinepi.2004.12.009

15 Kurman RJ, Carcangiu ML, Herrington CS, Young RH. WHO Classification of Tumours of Female Reproductive Organs. 4th ed. Lyon: IARC; 2014

16 Prat J; FIGO Committee on Gynecologic Oncology. Staging classification for cancer of the ovary, fallopian tube, and peritoneum. Int $\mathrm{J}$ Gynaecol Obstet. 2014;124(01):1-5. Doi: 10.1016/j.ijgo.2013.10.001

$17 \mathrm{R}$ Core Team [Internet]. The R project for statistical computing. Vienna: R Foundation; 2016 [cited 2018 Feb 12]. Available from: https://www.R-project.org/

18 DecisionCurve: calculate and plot decision curves [Internet]. 2017 [cited 2018 Feb 12]. Available from: https://mran.microsoft.com/ snapshot/2017-04-22/web/packages/DecisionCurve/index.html

19 Vickers AJ, Elkin EB. Decision curve analysis: a novel method for evaluating prediction models. Med Decis Making. 2006;26(06): 565-574. Doi: 10.1177/0272989X06295361

20 Coussens LM, Werb Z. Inflammation and cancer. Nature. 2002;420 (6917):860-867. Doi: 10.1038/nature01322

21 Kundu JK, Surh YJ. Emerging avenues linking inflammation and cancer. Free Radic Biol Med. 2012;52(09):2013-2037. Doi: 10.1016/j.freeradbiomed.2012.02.035

22 Prodromidou A, Andreakos P, Kazakos C, Vlachos DE, Perrea D, Pergialiotis $V$. The diagnostic efficacy of platelet-to-lymphocyte ratio and neutrophil-to-lymphocyte ratio in ovarian cancer. Inflamm Res. 2017;66(06):467-475. Doi: 10.1007/s00011-017-1026-6 